\title{
Errata to:
}

\section{A Step by Step Approach to the Modeling of Chemical Engineering Processes - Using Excel for Simulation}

\author{
Liliane Maria Ferrareso Lona
}

Errata to:

L.M.F. Lona, A Step by Step Approach to the Modeling of Chemical

Engineering Processes, https://doi.org/10.1007/978-3-319-66047-9

In the original version of the book published, there were some errors in equations of chapters 4, 5, 6 and 7 which have been updated now in this version, as per author's request.

The updated online versions of these chapters can be found at https://doi.org/10.1007/978-3-319-66047-9_4

https://doi.org/10.1007/978-3-319-66047-9_5

https://doi.org/10.1007/978-3-319-66047-9_6

https://doi.org/10.1007/978-3-319-66047-9_7

The updated online version of this book can be found at https://doi.org/10.1007/978-3-319-66047-9 